CONF-\$106151- - 1

FOR: IAEA Panel Report on Nuclear Based Techaiques For In vivo studg of Human Body Composition

APPLICATIONS OF NUCLEAR TECHNIQUES

FOR IN VIVO BODY COMPOSITION STUDIES

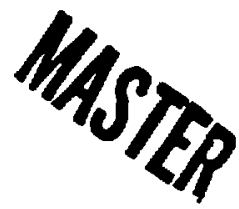

AT BROOKHAVEN MATIONAL LABORATORY

by

S. H. Conn, R. J. Ellis, D. Vartsky, A. N. Vaswani

and L. Wielopolski

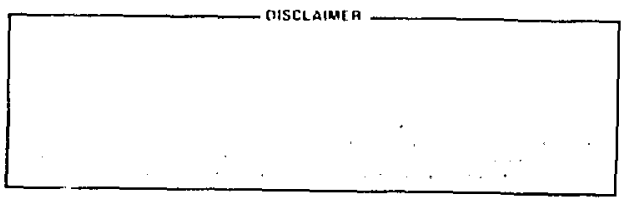

Medical Research Center

Brookhaven National Laboratory

Upton, New York 11973 
1. HISTORICAL DEVELOPMENT

Brookhaven National Laboratcry (BNL) has long been involved in research on calcium teabolise. When it became apparent that it was possible to nasure total body calcium, BNL actively undertook the development of such a facility.

In 1967-1968, a research program was begun with the goal of developing an in vivo total body neutron activation system. The neutron source eaployed wa a 14 Mev Texas Muclear generacor in use in the Physics Departwent. At the sare time, number of $a, n$ sources: ${ }^{238}$ PuBe, ${ }^{210}$ PoBe, and 241 ambe, were investigated.

It was also necessary to deterwine the absolute calibration for the measurement of calcium with an Alderson phantom. The uniformity of the thermal reutron flux and the flux density were also measured in a variety of phantow. The effects of polyethylene moderators were studied as part of the effort to achieve the highest possible uniformity in flux density in the phantows. The results of these various studies were first reported at the Conference on Progress and Problems in Neutron Activation at SURRC in East Kilbride, in 1969.

It took approximately a year after the completion of the phantom studies to obtain permission Eron the BNL Human Studies Committee to activate the first human auject. The first paper on in vivo activation analysis of calcium in wan at BAL was published in 1970. The results of the studies of 14 Mev neutrons and the lower energy neutrons from "portable" $\alpha, n$ sources were both reported at that time.

The studies ware continued and broadened. Approximately one year later, in 1971, a report was published on the measurement of total body 
nitrogen, calcium, sodium, and chlorine in seventeen patients with conditions ranging from wetastatic breast cancer to osteoporosis and chronic renal failure.

The neutron generator used for all of these studies was located in the Phys ics Building. Thus, it was necessary to transport the patients very quickly by ambulance to the whole-body counter situated in the Medical Cencer. A police escort was required to clear the way for the ambulance used for transport to ensure maximum road safety on the trip to the Medical Center.

The studies with neutron activation were continued with this neutron source for approximately two years. About two hundred activations were performed. During this period, a new $700 \mathrm{Ci}{ }^{238}$ PuBe neutron activation lacility was constructed in the BNL Medical Research Center. The discance of this new facility, from the whole body counter in the BNL hospital can be covered in approximetely three minutes. The absolute calibration of the system for the measurement of total body levels of calcium, sodium, chlorine, and phosphorus, was developed.

To date, well over 2,500 activations have been carried out on both normel subjects and patients with a wide variety of diseases, particularly osteoporosis and renal osteodystrophy (see section 3). This was the first $\alpha, n$ neutron activation facility designed specifically for clinical use and constructed in a hospital emvironment. The radiation dose to the patient was reduced to $270 \mathrm{mrem}$, the smellest dose delivered by an existing neutron activation facility $(1,2)$.

In 1977, BKL built the most sensitive and highly developed system for the in vivo measurement of cadmium in liver and kidney (3). It employed 
$85 \mathrm{Ci}$ of ${ }^{238}$ PuBe in a highly shietded collimated arrangement. The collimator was made of epoxy resin heavily doped with $\mathrm{Li}_{2} \mathrm{Co}_{3}$ and ${ }^{6} \mathrm{LiF}$. The detection limits (2SD) for Cd were $2.2 \mathrm{mg}$ for kidneg and $1.0 \mathrm{\mu g} / \mathrm{g}$ (wet weight) for the liver, with a localized dose of 470 mrem. This cadmium facility was installed in a specially designed 34 -foot trailer. This transportable facility can be moved to various locations for use in epidemiological studies. It was used in one major field atudy to measure Cd in the kidney and liver of workers at a cadmium smelter. The ${ }^{238} \mathrm{Pu}, \mathrm{Be}$ source and shielding have been replaced in the facility with a ${ }^{252} \mathrm{cE}$ source and certified IAEA shipping cask. This alteration has achieved an improved sensitivity simultaneously with a significant lowering of the dose to the subject. It has also eliminated the regulatory problems of transporting plutoniun through various localities. Transportation with the ${ }^{252}$ cf source presents far fewer problens.

Bin reported in 1971 on studies of total body nitrogen based on the $(n, 2 n)$ reaction in both normal subjects and in a variety of patients. More recently (1978) an improved system was developed for the measurement of total body nitrogen with the prompt-gaman neutron activation technique (4). The body nitrogen counts are measured simultaneously with total body hydrogen. The latter measurewent is then used as an internal standard for determination of total body nitrogen. The radiation dose delivered to the skin for the bilateral scan geometry of the patient is less than 45 mrem. The precision of the body nizrogen measurement in a human subject is approximate 1 y $3-4 \%$.

The prompt-gaman nitrogen mezaurement facility has been used extensively for the past three years. Cancer patients on various types of 
dietary supplementation and obese patients on protein-sparing diets have been studied. Data on a control group of normal individuals provide she requis ite basel ine informtion.

In the last two years, the BNL program has expanded to include a number of other nuclear technologies applied to medical problems. Iron is currently measured by nuclear resonance scattering (NRS) in pitients with thalassenia. This technique holds promise for other elements as well. Presencly, an x-ray fluorescence (XRF) technigue is being developed for the measurenent of L-x-rays from. lead deposited in the tibiae of human subjects.

\section{TECHNICAL DEVELOPMENTS}

There has been a long series of technical developments in the various nuclear technologies at Brookhaven culrinating in "state-of-the-art" techniques. The theoretical considerations that lead to these developments have been detailed in references (5). The factors involved in selecting the neutron sources for total body neutron activation, the type and positioning of the moderator and radiation dose to the subject have all been presented $(4,5)$. Consideration of these factors indicated that 4.0 Mev neutrons have an overall advantage of 2 relative to 14 Mev neutrons in IBWAA. Further, wltiple $(a, n)$ sources in a broad-ben geonetry and simultaneous bilateral exposure have an advantage of 3.6 relative to $14 \mathrm{Mev}$ neutrons from a cont inuous bean neutron generator. Portable $(a, n)$ sources provide ease of operation and high precision from the constant output of neutrons.

A significant technological advance was the development of a portable $(\alpha, n)$ neutron activation facility for measuring cadmium in vivo in kidney and 1 iver of the non-industrially exposed population. This facility was 
mounted in a 34 foot trailer. This mobile unit can easily be moved around the country for epidemiological studies as well as industrial exposure studies. Recently, the neutron source was changed from $238 \mathrm{Pu}$, Be to ${ }^{252} \mathrm{cf}$ which decreased radiation dose without a loss in sensitivity but greatly increased the ease of moving the trailer. The present mobile system exceeds all IAEA regulation for the transportation, shielding and use of ${ }^{252}$ cf sources.

A technique for the measurement of body iron utilizing nuclear resonant scattering of gamm rags has been developed (6). $847 \mathrm{keV}$ photons emitted frow a gaseous ${ }^{56}$ Mncl source are resonantly scattered from 5 Fe present in the body. Measu-fant is made using large volume Ge(Li) detectors. The spatial uniformity of activation, the sansitivity of the detection system and the limits of detection have been investigated. Measurements were made on a liver phantom. The resonance scattering technique permits determination of normal levels of Fe in the liver with a radiation dose of 2 rem.

A non-invasive measure of the skeletal levels of lead was developed by an $x$-ray fluorescence technique (XRF) as part of a toxicological study of lead in man. With this technique it will be possible to relate body burdens of lead to blood lead levels and to other indieators of biological effect frox lead. The instrument will be calibrated and validated for the measurement of absolute levels of lead in the skeleton. When fully operational the system will be installed in an existing wobile facility designed for the field study of internally deposited cadmium.

The most recent applications development involved a pulsed Van de Graff generacor as a source of pulsed neutrons, for the feasibility measureraent of lung silicon by inelastic scattering of fast neutrons. 


\section{CLINICAL APEL ICATIONS}

The clinical usefulness of the BNL total body neutron astivation analys is (TBNAA) program is best demonstrated by the studies involving the weasurement of total-body calcium. This measurement provides data useful for the diagnosis and magement of me tabol ic bone disorders. It should be emphasized, however, that wile most of the applications, to date, have involved calcium and phosphorus, the measurement of sodium, chlorine and nitrogen also appear to be useful clinically.

Total-body calcium weasurements utilizing TBNAA have been used in studies of csteoporosis to establish absolute and relative deficits of calcium in patients with this disease in comparison to a normal contrast population. Changes in tocal-body calciun (skeletal mass) have also been useful for quantitating the efficacy of various therapies in osteoporosis. Serial measurements over periods of years provide long-term balance data by direct measurewent with a higher precision $( \pm 3 \%)$ than is possible by the use of any other technique.

In the renal osteodystrophy observed in patients with renal failure, disorders of both calcium and phosphorus, as well as electrolyte disturbances, have been studied. The masure of total-body level s of these elements has given the clinician useful data upon which to evaluate dialysis therapy.

The measurement of bone changes in endocrine dys functicn have been studied, particularly in patients with thyroid and parathyroid disorders. In parathyroidectomy, the measurement of total body calcium, postoperatively, can indicate the degree of bone resorption. Changes in 
skeletal metabolism and body composition in acromegaly and cushing's disease have also been investigated by TBNAA.

Levels of cadmium in liver and kidney have also been measured in vivo by prompt gamma neutron activation and associated with hypertension, emphysem and cigarette smoking. These studies have demonstrated an increased body burden of Cd for cigarette smokers.

Total body nitrogen and potassium measurements serve as indices of protein and muscle mass and are useful in studies of the interrelation of cancer, diet and nutrition. An essential requirement in these studies is the in vivo measurement of changes in body composition, primarily revealed by nitrogen content. Currently, the optimal method for measurement of total body nitrogen is prompt-gamma neutron activation.

These are some of the clinical applications involving in vivo neutron activation that have been performed to date. A more detailed summary will be found in references $(1,2)$. Clearly, these applications have only indicated the enormous potential of this technique. There can be little question that in vivo neutron activation is a useful addition to the techniques for medical research which provides new and previously unavailable informe tion.

The object of the studies with the nuclear resonance scattering technique is to measure body deposits of iron in clinical studies involving chelation therapy of patients with Thalassemia major. The portable XRF system provides a rapid and accurate screening test to determine lead exposure in any population at risk. On the basis of in vivo measurement of lead body burdens and the above indicators of biological effect, it should be possible 
to set more precise criceria for permissible lead exposure in the occupationally exposed populations,

\section{RESULTS}

\subsection{Total-bocy measurement of calcium}

4.1.1. Normals: For the study of changes in skeletal calcium in me tabolic bone disorders, it is first necessary to take into account the normal changes with age. The non-invasive nature of the TBNAA technique and the Low levels of radiation dose employed have made possible the study of normal subjects (7-9). A mathematical model for the prediction of nomal totalbody calcium levels in terms of age, sex and body habitus has been developed for use as a reference (7). It is also of physiological in terest and clinical usefulness to relate skeletal mass (total calcium) to muscle mass (total potassium) (10).

4.1.2. Osteoporosis: Total body calcium (TBCa) measurements utilizing IBNAA have been used in studies of osteoporosis to establish absolute and relative deficits of calcium in patients with this disease in comparison to a normal contrast population (11-16). These studies have demonstrated that a decrease in total bone mass is a normal concomitant of the aging process. Further, this phenomenon is acceleraced in certain individuals, particularly postmenopausal women. A diagnosis of osteoporosis is reasonably certain when compression fractures cccur. Unfortunately, prior to the occurrence of these fractures, it is difficult to distinguish between an osteoporotic individual and a normal person matched for sex, age and body habitus on the basis of present criteria. Accurace quantification of bone mass is diffcult to achieve with the present state of the art; small changes that occur 
in the early stages of ostaoporosis do not mifest themselves with present methods of weasurement.

Clearly the assumption is mode that there is a definite relation between the level of bone mass (to wich the degree of osteopenia is inversely proportional) and the occurrence of compression fractures. On this basis, accurate measurement of bone mass is highly desirable. If there exists a critical level of bone mss for an individual (in terms of height and weight), it is of great value to determine this threshold value below which the risk of structural failure is sufficiently great as to warrant therapy. Total body neutron activation analysis (TBNAA) permits the direct in vivo measurement of total calcium sontent of the body, and hence skeletal mass, to be made with as high a degree of precision as $\pm 2 \%$ (2SD).

A number of clinical trials have been conducted with total body calcium (TBCa), measured by TBNAA, as the end point of efficacy (17-22). For example, Wallach (19) reported that $50 \%$ or more of osteoporotic women, treated with porcine calcitonin (100 MRC units dose) showed clinical improvement along with a mean increase of $3-9 \%$ in $\mathrm{TBCa}$.

In another recent study, the effect of therapy which utilizes growth hormone to stimulate bone formation (20), and simultaneously inhibits bone resorption with calcitonin, was evaluated in patients with primary osteoporosis (21). The technique of TBNAA was again used to measura TBCa. No significant increase in skeletal mass (TBCa) occurred during the low dose human growth hormone regimen. An increase in skeletal mass, however, was observed in almost all patients following the high dose growth hormone regimen. Although this study must be considered to be of preliminary nature, 
the magnitude of the response in calcium balance suggests that skeletal mass can be increased in osteoporosis if combination therapy is employed (21). In another study, combined treatment of osteoporotic patients with salmon calcitonin, sodium fluoride and calcium, over a period of 24-33 months, significantly increased the man TBCa $(p<0.05)$ (22). This increase indicates that treatment prevented further development of osteopenia.

The efficacy of synthetic salmon calcitonin (sCT), in the treatment of senile male osteoporotics, was also studied in terms of TBCa and bone mineral content (BMC) of the radius at six nonth intervals (23). Males, 50 or more years of age, with diffuse demineralization and collapse of one or more vertebrae, were studied. Thirty-one patients were randomly divided into three groups: (1) a control group receiving muliivitamins, (2) a calcium supplemental group receiving $1 \mathrm{~g} \mathrm{Ca}$ and multivitamins, and (3) a calcitonin group receiving 100 MRC units sCT daily plus calcium and multivitamins. No significant changes in TBCa were observed among the three groups during the first year. However, the group wich received $\mathrm{sCT}$ showed significant increases in TBCa $(4-6 \%)$ at 18 and 24 months. These increases in TBCa were not reflected by BMC measurements.

4.1.3. Renal osteodystrophy: Renal osteodystrophy in patients with renal failure has been studied extensively $(24-29)$. Disorders of both calcium and phosphorus, as well as electrolyte disturbances were reported. Total-body levels of $\mathrm{Ca}$ and $\mathrm{P}$ give the clinician useful data upon which to base therapeut ic regimes. Changes in the concentration of calcium and phosphorus in the dialysate are rapidly reflected in the total body $\mathrm{Ca}$ and $P$ measurements of the body. The dialysate concentration cas then be adjusted to raduce the loss of calcium associated with dialysis ( 30$)$. 
The effect of pharmacologic doses of 25-hydroxycholecalciferol (25OHD) On $\mathrm{TBCa}$ and $\mathrm{BMC}$ of the distal radius was evaluated in renal osteodystrophy patients on hemodialysis (31). Two groups were studied. Group I received oral 25-OHD for 100 weeks. Group II received supplemental oral calcium only. Both groups were hemodialyzed with $6.5 \mathrm{mg}$ percent dialysate $\mathbf{C a}$.

The TBCa increased significantly in members of Group I; the change in BMC was variable. No change in TBCa or BMC was observed in Group II patients. It was concluded that the observed TBCa reflected an increase either in bone or in soft tissue $\mathrm{Ca}$, or both.

4.1.4. Paget's disease: Serial measurements of TBCa were made in twenty patients with generalized symptomatic Paget's disease while they received lony $=2 \mathrm{~m}$ calcitonin therapy (32). Total body calcium had increased by an average of $22 \%$ above predicted normal values prior to calcitonin therapy; it decreased significantly (4\%) during long-term calcitonin therapy. Totalbody phosphorus, nitrogen and sodium also decreased during therapy. These data confirm histologic evidence of disappearance of pagetic bone, and radiographia evidence of a decrease in bone volume during calcitonin treatment.

4.1.5. Endocrine dysfunction:

a. Thyroid and parathyroid disorders: Changes in skeletal wass in patients with endocrine dysfunctions have been studied, particularly in those patients with disorders of thyroid (33) and parathyroid (34). After parathyroidectomy, the level of TBCa is indicative of the degree of bone resorption. On this basis, surgeons have gauged the effectiveness of the removal of the hypertrophic parathyroids. 
b. Cushings's syndrome: Skeletal metabolism and body composition were investigated in patients displaying Cushing's syndrome (35). The technique of TBNAA was utilized to measure skeletal mass (TBCa) and body ca position. Eight patients with Cushing's syndrowe vere gtudied. In addition serm concentration of 25-hydroxycholecalciferol (25-0HD) was measured in four of these patients, and in an additional 17 patients who were receiving exogenous glucocorticoids.

Prior to therapy, skeletal muss (TBCa) and lean body mass $\left({ }^{40} \mathrm{~K}\right)$ were considered to be decreased in five of siven patients. The osteopenia was generally not corrected as deterwined in follow-up activations subsequent to treatment of the Cushing's syndrome. The only significant increases in total-body calcium occurred in two patients who presumably had not completed body growth. Serum levels of 25-0HD were in the notmal range in the spontaneous Cushing's, as well as the Iatrogenic Cushing's syndrome patients.

c. Acromegaly: The effect of hyper-somatotropism on skeletal metabolism was investigated in ten acromegalic inividuals (36). The mean TBCa was $9 \%$ higher than the predicted normal values. The ratio of TBCa to lean body mass $\left(40_{K}\right)$ was reduced in four subjects. Although this effect may be the result of a greater increase in soft tissue mass than in skeletal mass, only two patients had total-body $\mathrm{Ca}$ levels which were less than the predicted values. These two subjects could be considered to have osteopenia.

4.1.6. Rheumatoid arthritis: The evaluation of diffuse osceoporosis in rheumntoid arthritis (RA) remains controversial. An important problem associated with the disease is the role of long-term corticosteroid therapy 
in the development of osteopenia. In the present study, IBCa was evaluated in 19 women with $\mathrm{RA}$, with and without corticosteroid treatment (37). The skeletal mass, as measured by TSNAA, was within normal limits in seven patients with no steroid treatment: it decreased in the remaining patients on corticosteroid treatment. The decrease in IBCa was most marked in postmenopausal women. Thus age is a significant lactor in the development of osteoporosis following prolonged corticosteroid therapy.

4.1.7. Alcoholism: Total skeletal mass was measured in two groups of chronic alcoholic subjects with and without Laennec's cirrhosis (38). No significanc ioss of skeletal calcium was determined. However, there was a marked loss of lean body mass (total body potassium) in alcoholic subjects with cirrhosis.

4.1.8. Osteogenes is Imperfecta: Three post meropausal women with osteogenesis imperfecta tarda (OI) were treated daily with salmon calcitonin and calcium supplements for 12 to 33 months (39). IBNAA measurements of TBCa revealed a marked deficit in these patients, exceeding that found in severely osteoporotic women. In one patient, the rapid loss of TBCa was partially reversed after twelve months of treatment. The second patient showed an increased $\mathrm{TBCa}(9 \%)$ after 33 months of treatment. Inconclusive results were obtained for a third patient who was receiving treatment with corticosteroids for as thma. The results confirm the findings of previous studies that supplied calcitonin to children with OI, and suggest that calcitonin may also be of benefit to adults with OI.

4.1.9. Myotonic dystrophy: Muscular wasting and endocrine disturbance are marked in most patients with myotonic dystrophy (ID). Six of seven MD patients studied exhibited a marked deficit in total body potassium (TBK); cal- 
cium, phosphorus and chlorine levels remained normal (40). MD appears to be one of the few metabolic disorders studied in which the relatively constant relationship between TBK and TBCa is alteied. These daca suggest that low levels of circulating androgen in MD are not necessarily associated with a decreased skeletal mas.

4.1.10. Thalassemia: Long-term administration of calcitonin to five patients with thalassemic bone disease produced clinical improvement; however, a net gain in IBCa occurred in only one patient (41). The total lody calcium levels ranged from 357 to $665 \mathrm{~g}, 12$ to 547 below the normal levels. These patients exhibited the greatest calcium deficits seen in any of the subjects studied.

4.1.11. Post-Gastrectogy: The skeletal mass and serum levels of 25-hydroxy-vitan in $D$ were studied in 18 post-gastrectomy patients (42). The skeletal mass, measured by TBNAA, was decreaged significantly in 3 men and 3 wonen, one-third of the total cases studied. In the remainder of the patients, the TBCa values were within normal limits. The presence of spinal osteoporosis was suspected in only two of the patients on the bas is of radiological examination. The frequency of osteopenia, as evaluated by TBCa, was higher than the 10\% previously reported. There was no correlation between time since gastrectomy and changes in TBCa levels. In some patients, marked lower serum 25-OtD and elevated plasma alkaline phosphatase were observed. All patients with low TBCa had elevated alkaline phosphatase levels. There was no correlation between TBCa and serum 25-0HD. 
4.2. Total-body sodium and chlorine

4.2.1. Normal adults: IBMA was used to determine the absolute levels of total body sodium (TBNa) and total body chlorine (TBCl) in 81 normal adults (43). For the age span studier, ( 30 to 90 years), the mean values of TBNa and TBC1 remained relatively constant for wales, but decreased slightly for females beyond sixty years of age. The TBNa and TBCl values were nornalized for body dimensions (weight, height, body surface area) as well as age and sex. In addizion, TBNa was related to skeletal mass (TBCa) and lean body mas (TBR). The quantity of body sodium in excess of the chlorine space was determined. This value, defined as sodium excess, was significanty correlated with TBCa. The values for TBNa, TBCl and sodium excess obtained in the normal population study have served as baseline levels for the clinical studies.

4.2.2. Total and exchangeable sodium in hypertension: The altered distribution of extracellular fluid (ECF) and intracellular fluid (ICF) was studied in hypertensive uremic patients (44). Both volume expansion and increased vasoconstrictor activity are alledged to influence blood pressure in tialgsis patients. TBNAA, radioimmunoassay and radioisotopic techniques were used to measure the following parameters: IBNa, IBCl, exchangeable sodium (NaE), total body water (TBW), plasma renin activity (PRA) and lean body mass (TBK). The dialysis patients were divided inco two groups, retrospectively, based on the distribution of the total body water. The members of Group A (with normal percentage distribution of TBW between ECF and ICF) have minimal hypertension, while those in Group B (with an abnormal percentage distribution of $T B W$ ) have significantly more severe hypertension. 
Blood pressure was significantly elevated in patients in Group $B$. NaE/TBR and PRA were elevated above control levels in all patientis, but there was no significant difference between the elevated levels of Group A and Group $B$ individuals. Neither volume expansion nor increased vasoconstrictor activity appears sufficient to provide a basif for the hypertension.

\subsection{Total body nitrogen}

Changes in body composition of cancer patients relative to their dietary and nutritional status have been studied (45-47). Specificaliy, it was desired to determine whether various nutritional regimes can either prevent or minimize loss of total body nitrogen. The importance of maintaining positive nitrogen balance in cancer patients is obvious. Total body nitrogen (TBN) was measurad with the use of the crrent technique of neutron activation (prompt gamma, ${ }^{14} \mathrm{~N}(\mathrm{n}, \mathrm{y}){ }^{15} \mathrm{~N}$ reaction). Quantitative measurement of TBN was made in both normal subjects (for baseline data) and in cancer patients. Measurements of the latter will be related to nutritional support regimes and anti-neoplastic therapeutic programs. TBN and TBR have been used as indices of protein and total cellular mass. 4.4. Cadmium in liver and kidney

The internal deposition of cadmium is recognized as a potentially serious health problem. Significant Cd accumulations occur in the liver and kidneys. For the general population, the major health hazard appears to be irreversible kidney danage. Cd deposition in the kidney has been proposed as a causative factor in human hypertension, while lung $C d$ has been associated with emphysem. 
Cd concentrations in kidney and liver are being measured by promptgamma neutron activation in a program currently underway (48-50). Since prolonged industrial exposure to $\mathrm{Cd}$ is correlated with kidney damage a study is being conducted to determine the dose-effect relationship between the accumblation of $\mathrm{Cd}$ in occupationally exposed subjects. The portable promptgamma neutron activation facility was constructed to enable these studies to be carried out at industrial sites (50). An evaluation of the critical concentration for the kidney has demonstrated a value near $300 \mu \mathrm{g} / \mathrm{g}$ for the renal cortex (50).

\subsection{Iron in liver and heart}

To date, five patients with Thalassemia have been measured by the nuclear resonance scattering technique. The limits of detection are adequate to measure the level of iron in the liver. However, for the measurement of iron in the heart greater sensitivity would be desirable. It is not possible yet to measure normal heart iron levels in normal subjects.

\subsection{Lead in tibia}

To assess the feasibility of measuring bone lead concentrations noninvasively in vivo, characteristic $L$-rays were induced post mortem in the superficial tibial cortex of intact legs in five adults who had no history of occupational history to lead, using an external source of ${ }^{125} I$ (51). Tibial lead concentrations found subsequently by flameless atomic absorption spectroscopy in the same bones varied from 15 to $35 \mathrm{\mu g} \mathrm{Pb} / \mathrm{g}$ wet weight, within the modern normal range. The linear correlation coefficient between $x$-ray fluorescence signals and lead concentration was $r=0.92$. 
Radiation dose of 1 rem to $1 \mathrm{~cm}^{2}$ of skin yielded net lead peaks which ranged from one to seven times the standard deviation of background, while doses to the adjacent bone ma rrow were about 60 mrem.

Above are 1 isted some of the many clinical applications of in vivo neutron activation that have been carried out, or are currently underway. The enormous potential of the technique for medical research is clearly demonstrated. In viro neutron activation is a powerful technique for medical research, and is providing new and previously unavailable information.

\section{PLANS FOR EUTURE}

The Brookhaven group will cont inue to develop the above uuclear technologies for use in clinical research studies. Continued development has improved the sensitivity of measurements along with a reduction in radiation dose.

The most recent study evaluated the feasibility of quantitating the level of silicon in the lung by inelastic scattering of neutrons ( 52 ). This technique employed pulsed neutrons from a Van de Graff generator. Further development should lead to clinical trials.

It is planned to continue the nuclear resonance studies for the measurement of iron body burdens by improving the collimation, shielding and the radiation sources. It is hoped to be able to measure normal levels of iron in the heart. The technique will then be used in clinical senters now studying Thalassemia Major utilizing chelation wethods for reducing iron stores. These studies have, in the past, been hampered by a lack of sufficiently sensitive quantitative measurement of the heart concentration of iron. 
The XRF instrument will be further developed to improve the sensitivity for the measurement of lead. The system will be calibrated and finally validated by the analysis of intact amputated legs, as described above. When fully operational, the final system will be installed in an already existing mobile facility, designed for the field measurement of cadmium. Thus, it will be possible to measure both elements in the same individual during field studies.

The whole range of pulsed neutron activation techniques (in-beam, prompt, and delayed) is being re-evaluated. Compact portable neutron generators (both $(D, D)$ and $(D, T)$ ) are being developed for potential clinical applications. These compact devices ( $s$ cm length) are ideally suited for portable facilities.

New applications applying both old and new nuclear technologies to medical problems will continue to be explored. 
The submitted manuscript has been authored under contract \#.DE-ACO2-76CHOOO16 with the U. S. Department of Energy. Accordingly, the U.S. Government retains a nonexclusive, royalty-free 1 icense to publish or reproduce the published form of this contribution, or allow others to do so, for U.S. Governont purposes. 


\section{REFERENCES}

1. CotN SH: The present status of in vivo neutron activation analysis in clinical diagnosis and therapy. Atomic Energy Review IAEA, Vol 18, No. 3 Vienna, (1980).

2. COHN SH: In vivo neutron activation analysis: State of the art and future prospects. Med Physics. 8, 145, (1981).

3. VARTSKY D, ELLIS $\mathrm{KJ}$, CHEN NS AND COHN Sh. A facility for in vivo measurement of kidney and liver cadmium by neutron capture prompt-gamma ray analysis. Phys. Med. B Biol. 22, 1085-1096, (1977).

4. VARTSKY D, ELLIS $\mathrm{KJ}$ AND COHN SH. In vivo measurement of body nitrogen by analysis of prompt-gama from neutron capture. J. Hucl. Med. 20, $1158,(1979)$.

5. COHN SH, FAIRCHIID RG, SHUKLA RK: Theoretical consideration in the selection of neutron sources for total-body neutron activation analys is. Phys. Mrd. Biol. 18, 648 (1973).

6. VARTSKY D, ELLIS $\mathrm{KJ}$, HULL DM, AND COHN SH. Nuclear resonant scattering of gamma-rays - A new technique for in vivo measurement of body iron stores. Phys. Med. Biol. 24, 689-701, (1979).

7. COHN SH, VASWAN I AN, ALO IA JF, ROGINSKY M, ZANZI I, ELIIS KJ: Changes in body chemical composition with age measured by total-body neutron activation. Metabolism 25, 89 (1976).

8. COHN SH, ABESAMIS C, ZANZI I, ALOIA JE, YASUMURA S, ELLIS KJ: Body elemental composition: Comparison between black and white adults. Am. J. Physiol. 232, 419 (1977). 
9. COHN SH, ABESAMIS C, YASUMURA S, ALO LA JF, ZANZI I, ELLIS KJ: Coluparative skeletal mass and bone density in black and white women. Metabo1 ism 26, 171 (1977).

10. ELLIS $\mathrm{KJ}$, COHN SH: The correlation between skeletal mass and muscle mass in man. I Appl. Physiol. 28, 455 (1975).

11. COHN SH, ELLIS KJ, WALLACH S, ZANZI I, ATKINS HL, ALOIA JE: Absolute and relative deficit in total skeletal calcium and radial bone mineral content in osteoporosis. J. Nucl. Med. 15, 428 (1974).

12. ALIA JF, ELLIS KJ, ZANZI I, COPM SH : Photon absorpt iometry and skeletal mass in the treatment of osteoporosis. J. Nucl. Med. 16, 196 (1975).

13. ALOIA JF, VASWANI A, ATKINS HL, ZANZI I, ELLIS $\mathrm{KJ}$, COHN SH: Radiographic morphometry and osteopenia in spinal osteoporosis. J. Nucl. Med. 18, 425 (1977).

14. ALOIA JF, COHN SH, VASHaNI aN, ABESAMIS C, Ellis RJ, ZANZI I: Skeletal mass in postmenopausal women. Am. J. Physiol. 235 (1): E82 (1978).

15. ALOIA JF, COHN SH, ZANzI I, ABESAMIS C, ELLIS $\mathrm{KJ}$ : Hydroxyprol ine peptides and bone mass in postmenopausal and osteoporotic women. J. C1 in. Endoc. Metab. 47, 314 (1978).

16. COHN SH: Measurement of bone mass in osteoporosis. Calc. Tiss. 26, ] (1978).

17. COHN SH, DCMBROWSKI CS, HAUSER $W$, KLOPPER J, ATKINS HL. Effect of pOrcine calcitonin on calcium metabolism in osteoporosis. J. Clin. Endo. \& Metab. 33, $719(1971)$.

18. COHN SH, DOMBROWSKI CS: Ef fects of fluorine on calcium me tabolism in osteoporosis. Am. J. C1 in. Nutr. 24, 20 (1971). 
19. WALLACH S, COHN SH, ATKINS HL, ELLIS KJ, KOHBERGER R, ALO IA JE, ZANZI I: Effect of salmon calcitonin on skeletal nass in osteoporosis. Curr. Ther. Reg. 22, 556 (1977).

20. ALOIA JF, 2ANZI I, ELLIS $\mathrm{KJ}$, JOHSEY J, ROGINSKY $M$, WALLACH S, COHN SH: Effects of growth hormone in osteoporosis, J. $\mathrm{Cl}$ in. Endocrin. Metab. 43, $992(1976)$.

21. ALOIA JE, ZANZI I, VASWAN I AN, ELLIS KJ, COHN SH: Combination therapy for osteoporosis. Metabolism 26, 787 (1977).

22. ZANZI I, ALOIA JE, ELLIS KJ, VASWANI AN, COHN SH: Preatment of osteoporosis with salmon calcitonin, sodium fluoride and calcium. Metabolism (1978).

23. AGRAWAL R, WALLACH S, PEABODY R, TESSLER M, COHN SH: Treatment of seni le osteoporosis. (Abst. Proc. Mech. Bone Wash. D.C.) (1977).

24. COIN SH, CINQUE TJ, DOMBROWSKI CS, LETTERI JM: Determination of body composition by neutron activation analysis in patients with renal failures. J. Lab. Clin. Med. 79, 978 (1972).

25. LETTER I JM, ELLIS RJ, RUGGIERI S, ASAD S, COHN SH: Altered calcium metabolism in chronic renal failure. Kidney Int. 6, 45 (1974).

26. LETTER I, $J$, COHN SH: "Total body neutron activation analys is in the study of mineral homeostasis in chronic renal disease. Calcium metabo1 ism in renal failure and nephrolithias is. (DAVID, D.S., Ed.), John Wiley and Sons, Inc., New York 249 (1977).

27. COHN SH, ELLIS RJ, CASELNOVA RC, ASAD SN, LETTERI M: Correlation of radial bone mineral content with tztal body calcium in chronic renal fai lure. 3. Lab. $C 1$ in. Med. 86, 910 (1975). 
28. COHN SH, ELLIS KJ, MARTINO A, ASAD SN, LETTER I JM: LOSS of callcium from axial and appendicular skeleton in patients with chronic renal failure. Calcif. Tissue Res. 21, 216 (1976).

29. LETTERI JM, COHN SH: Body composition in chronic renal disease as measured by body neutron activation and whole body counting. Mineral and Electrolyte Metab. 1, 181 (1978).

30. ASAD S, ELLIS RJ, COHN SH, LETTER I M: Canges in total body calcium on prolonged maintenance hemodialysis with high and low dialysate calcium. Nephron 23, 223 (1979).

31. RLEINMAN LM, LETTERI JM, ASAD S, ELLIS RJ, COHN SH: Effects of 25 hydroxycholecalciferol on calcified tissues in uremia. Arch. Int. Med. 138, 864 (1978).

32. Hallach S, AVRaMides A, FLORES A, BEllavia J, COHN SH. Skeletal turnover and total body elemental composition during extended calcitonin treadoent of Paget's Disease. Metabolism 24, 745 (1975).

33. COHN SH, ROGINSKY MS, ALOIA JF, ELLIS RJ, SHUKLA KR: Alterations in skeletal calcium and phosphorus in dysfunction of the parathyroid. J. Clin. Endocrin. Metab. 36, 750 (1973).

34. COHN SH, ROGINSKY MS, ALOIA JE, ELLIS KJ, SHUKLA KR: Alterations in skeletal calcium and phosphorus in dysfunction of the parathyroid. J. Cl in. Endocrin. Metab. 36, 750 (1973).

35. ALOIA JF, ROGINSKY MS, ELLIS KJ, SHUKLA KK, COHN SH: Skeletal metaboIism and body composition in Cushing's disease. J. Clin. Endocrin. Metab. 39, 881 (1974). 
36. ALO IA JF, PETRAR Z, ELLIS KJ, COHN SH: Body composition and skeletal metabolism following pituitary irradiation in acromegaly. Am. J. Med. 61, $59(1976)$.

37. ZANZI I, ROGINSKY MS, ELLIS RJ, BLAU S, COHN SH: Skeletal mass in rheumatoid arthritis: A comparison with forearm bone mineral content. Am. J. Roentgenol. Radium Ther. Nucl. Med. 126, 1305 (1976).

38. ROGINSKY MS, ZANZI I, COHN SH. Skeletal and lean body mass in alcoholics with and without cirrhosis. Calif. Tissue Res. 21, 386 (1976).

39. ZANZI I, WALLACH S, ELLIS KJ, ALOIA JF, ATKINS HL, COHN SH: Long term treatment of osteogenesis imperfecta tarda in adults with salmon calcitonin. Curz. Ther. Res. 19, 189 (1976).

40. ZANZI I, ROGINSKY MS, ELLIS KJ, CCHN SH: Studies on body composition in patients with myotonic dystrophy. (Abst. Endocrine Society Meeting, 1976).

41. SHAI F, WALIACH S, COHN SH, BAKER RR: "Effects of chronic calcitonin adminigtration in the bone disease of Thalassemia". Clinical Aspects of Metabolic Eone Disease, Ford Hospital, Detroit, Michigan, Excerpta Medica (1972).

42. ZANZI I, SCHOEN M, ROGINSKY MS, ELLIS KJ, HOLT P, COHN SH: SkeletaI mass and serum levels of 25-hydroxyvitamin D in Postgastrectomy patients. (NORMAN, E.W., Ed.) (Proc. Third Workshop on Vitam in D, Asilomar, California. Publ. W. DeGruyter, New York. 859 (1977).

43. ELLIS RJ, VASWANI AN, ZANZI I, COHN SH: Total body sodium and chlorine in normal adult3, Metabolism 25, 645 (1976). 
44. BRENNAN BL, YASUMURA S, COHN SH, LETTER I M: Altered distribution of extracellular and intracellular fluid in hypertensive uremics. Kid. Inter. $17,364,(1980)$.

45. COHN SH, SAWITSKY A, VARSKY D, YASUMURA S, ZANZI I, ELLIS RJ: In vivo quantification of body composition in normal subjects and in cancer pat ients, Nutrition and Cancer 2, 67 (1980).

46. COEN SH, VARTSKY D, YASUMURA S, SAWITSKY A, ZANZI I, VASWANI AN, ELIIS $\mathrm{KJ}$ : Compartmental body composition based on total budy nitrogen, potassium and calcium. Am. J. Phys iol. 239, E524 (1980).

47. COHN SH, GARTENHAUS W, SAWITSKY A, RAI K, ZANZI I, VASWANI AN, ELLIS RJ, YASUMURA S, CORTES E, VARTSKY D: Compartmental body composition of cancer patients by measurement of cotal body nitrogen, potassium and water. Metab. 30, 222 (1980).

48. ELLIS RJ, MORGAN WD, YASUMURA S, VARTSKY D, ZANZI I, COHN SH: In vivo measurement of cadmium in an occupational ly exposed popularion. Fourth Int. Conf. on Nuclear Nethods in Environmental and Energy Research, Columbia, Ko., (1980).

49. ELLIS KJ, VARTSKY D, ZANZI I, COHN SH, YASUMURA S: Cadmium: In vivo measurement in smokers and non smokers. Science 205323 (1979).

50. ELLIS KJ, MORGAN HD, ZANZI I, YASUMURA 3, VARTSKY D, COHN SH. Critical concentration of cadmium in human renal cortex (dose $z=c=s$ studies in cadmium smelter workers. J. Toxicol. Environ. Heaith 7, 691 (1981). 51. WIELOPOLSKI L, SLATKIN DN, VARTSKY D, ELLIS KJ, AND COHN SH. Feasibi1ity study for the in vivo weasurement of lead in bone using $L x$-ray fluorescence. IEEE Trans. Nucl. Science, 20, 114-116, (1981). 
52. ETTINGER KV, MORGAN WD, MIOLA UJ, VARTSKY D, ELIIS KJ, WIELOPOLSKI L, COHN SH: Silicon measurement in a lung phantom by neutron inelastic scattering. Phys. Med. Biol. (submitted). 
Institute address

Medical Research Center Brookhaven Mational Laboratory Upton, Neyt York 11973, USA.
Name of person to contact for more information

Stanton H. Cohn

(576) 282-3591

Kenneth J. Ellis

(516) $282-3574$

\section{Cverall system performance}

Element(s) measured: $\mathrm{Ca}, \mathrm{Ha}, \mathrm{Cl}, \mathrm{P}, \mathrm{K}$ (whole body counting) Organ of interest: whole body

Radiation dose: $2.8 \mathrm{mSv}$ (whole body)

Peproducibility of measurement*: Ca $(1 \%)$, ila $\& \mathrm{Cl}(2 \%), P(4 \%), K(4 \%)$

No. of measurements possible per day $(8 \mathrm{hr}): 12 \mathrm{max}$. (8 routine)

In operation since (year): 1968

Irradiation device

Ho. and type of source: fourteen 5óci ${ }^{238}$ PuBe jources

Total Activity/Output ( $\mathrm{n} / \mathrm{s}$ at source): $1.0 \times 10^{8} \mathrm{n} / \mathrm{s}$ per source

Geometry: Total body, bilateral irradiation

Incident neutron flux density in body: $5 \times 10^{4} \mathrm{n} / \mathrm{cm}^{2} / \mathrm{sec}$ (thermal)

Exposure time: $300 \mathrm{sec}$

Uniformity of irradiation: $\pm 8 \%$ (themal flux)

Special features: $8 \mathrm{~cm} \mathrm{Bi}$ layer surrounded by im of concrete shielding

Counting device

Ho. and type of detector: $54 \times \mathrm{MaI}(\mathrm{TT}), 15 \times 5 \mathrm{~cm}$

Geometry: two $3 \times 9$ arrays, one above, one below supine body

Shielding: $122 \mathrm{~cm}$ concrete, $10 \mathrm{~cm}$ steel, $0.32 \mathrm{~cm} \mathrm{~Pb}, 0.16 \mathrm{~cm} \mathrm{Al}$

Measurement time: $900 \mathrm{sec}$.

Data evaluation: on-line computer-based multi-channel analyzer system

Costs (approximate, for replacement in 1981 in US5)

Irradiation device: sources $(\$ 70,000)$, shielding $(\$ 100,000)$

Detector device: detectors $(\$ 170,000)$, shielding $(\$ 500,000+)$

Electronics and data processing: $(\$ 150,000)$

* Alderson phantom with "standard man" composition 


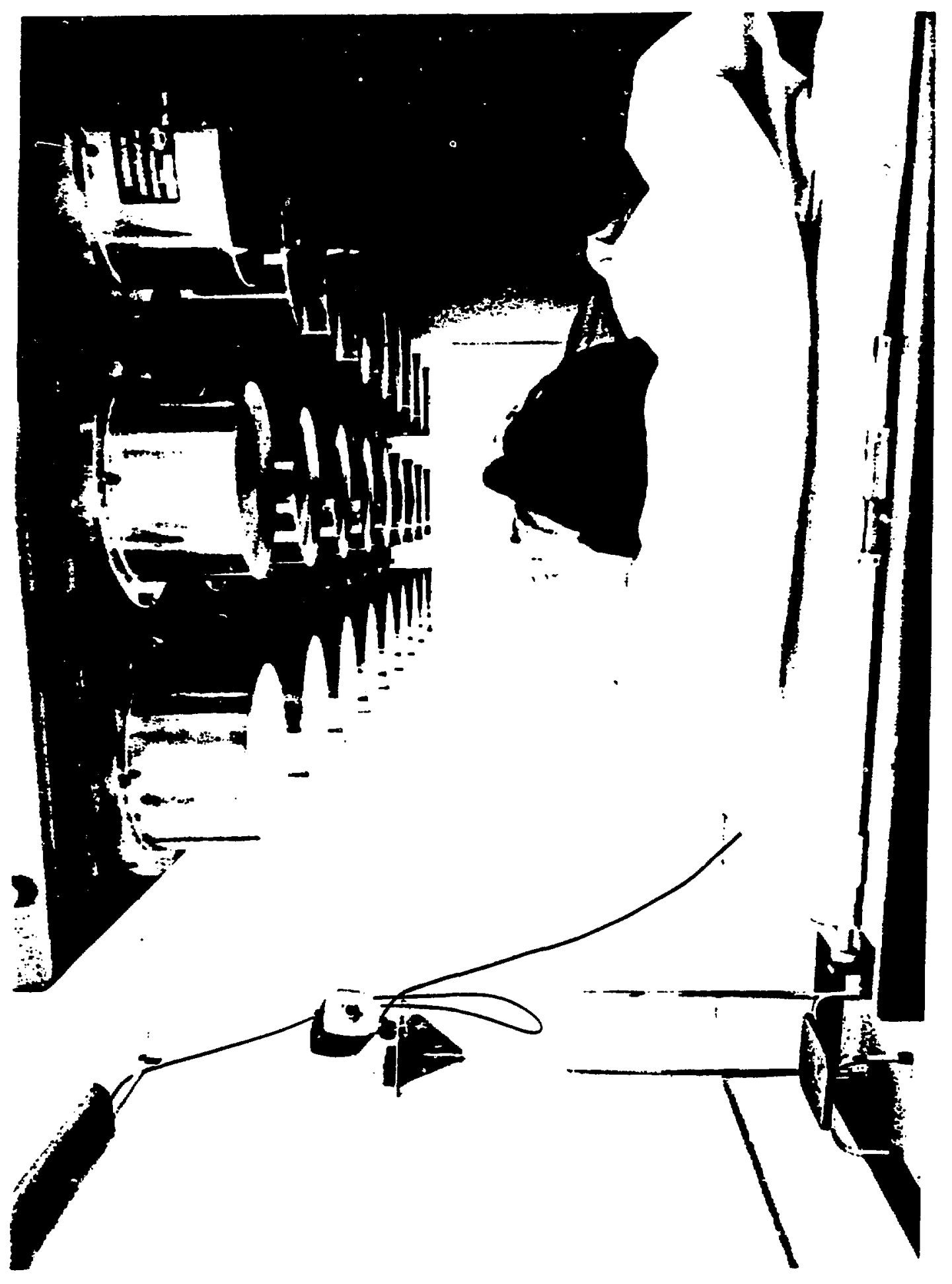




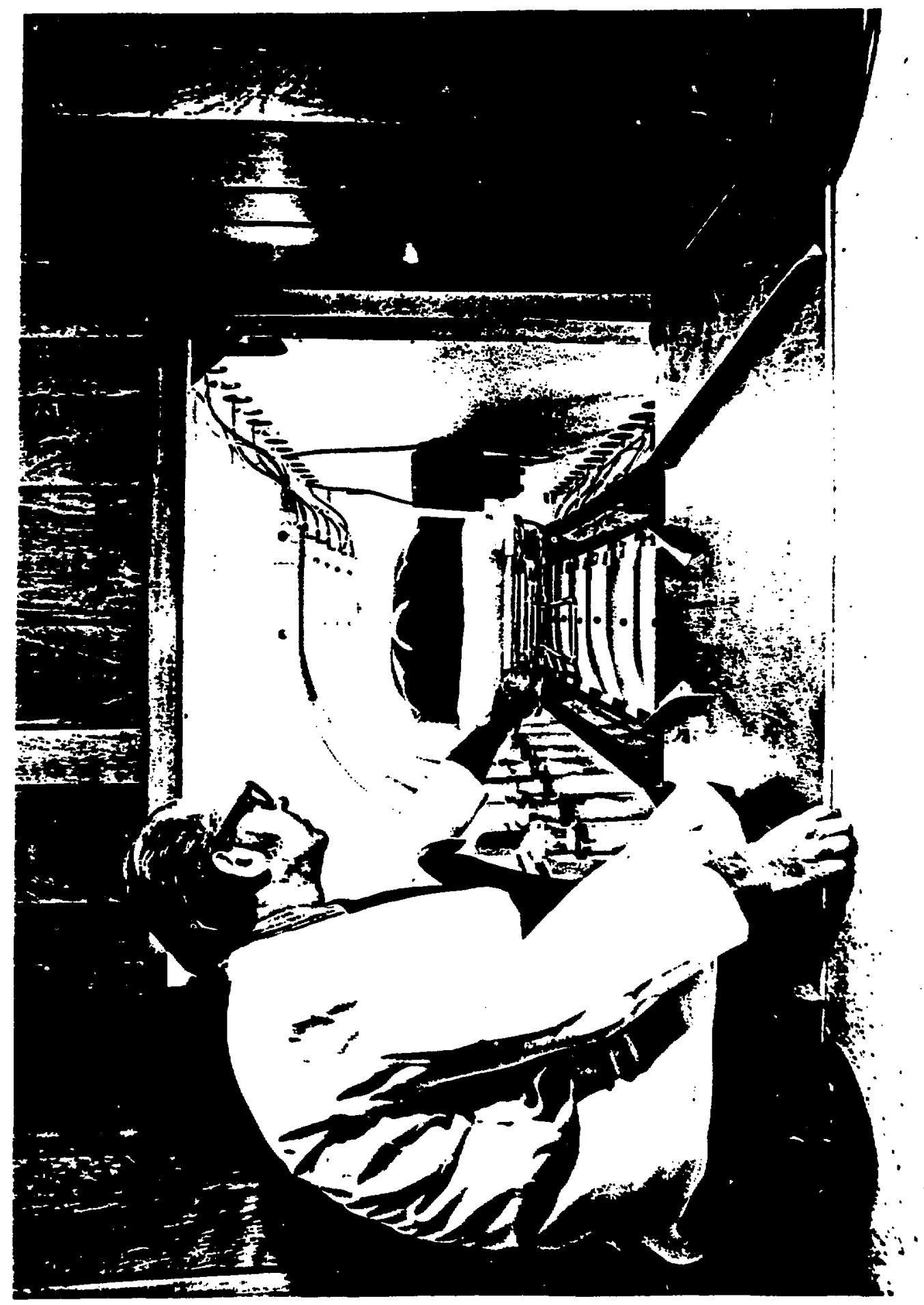


DESCRIPTION OF SYSTEM FOR IN VIVO NEUTRON ACTIVATION ANALYSIS

Institute address

Medical Research Center

Brookhaven National Laboratory

Upton, New York 11973 USA
Name of person to contact for more information

Dr. S.H. Cohn

(516) 282-3591

Dr. D. Vartsky

(516) $282-3637$

Overall system performance

Element(s) measured: $N$

Organ of interest: Whole body

Radiation dose: $0.50 \mathrm{mSv}$ (Skin dose)

Reproducibility of measurement: $4 \%$

No. of measurements possible per day $(8 \mathrm{hr}): 5$

In operation since (year): 1978

Irradiation device

No. and type of source: Two $42 \mathrm{Ci}{ }^{238} \mathrm{pu}, \mathrm{Be}$

Total Activity/Output ( $\mathrm{n} / \mathrm{s}$ at source): $: 2.3 \cdot 10^{8} \mathrm{n} / \mathrm{sec}$

Geometry: Total body (scanning geometry)

Incident neutron flux density in body: $7.2 \cdot 10^{3} \mathrm{n} / \mathrm{cm}^{2} \cdot \mathrm{sec}$

Exposure time: $2000 \mathrm{sec}$

Uniformity of irradiation for element $\&$ organ of interest: $4-6.5 \%$

Special features:

Counting device

No. and type of detector: $2 \times \mathrm{NaI}(\mathrm{TI})(15.24 \times 15.25 \mathrm{~cm})$

Geometry: Positioned above the body

Shielding: Epoxy resin + Li

Measurement time: $2000 \mathrm{sec}$

Data evaluation: On-line computer based multichannel analyzer and bed

Special features:

control system

Costs (approximate, for replacement in 1981 in US\$)

Irradiation device: $\$ 23,500$

Detector device: $\$ 7,500$

Electronics, data processing and control: $\$ 31,500$ 

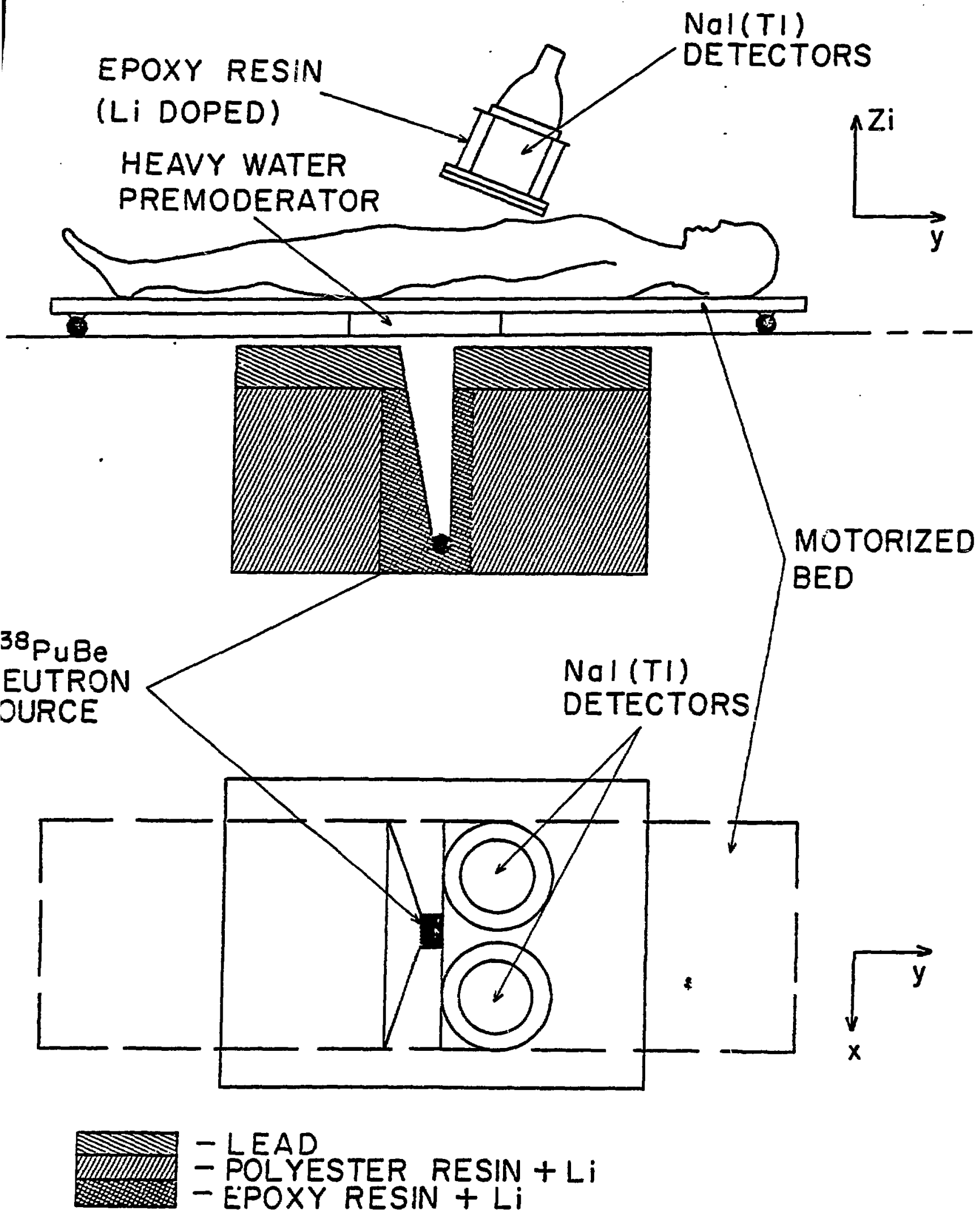

$-L E A D$

- POLYESTER RESIN + Li

- EPOXY RESIN + Li 
Appendix - 7.3

IN VIVO CADWIUM MEASUREMENT

Institute address

Medical Research Center Brookhaven National Laboratory Upton, New York 11973 USA

(Medical Physics Group)
Name of person to contact for more information

Kenneth J. Ellis

(516) 282-3574

Stanton H. Cohn

(516) 282-3591

\section{Overall system performance}

Element(s) measured: Cd Organ of interest: Kidney, liver Radiation dose: $4.7 \mathrm{mSv}$ (max. Skin dose)

Reproducibility of measurement : $5 \%$

No. of measurements possible per day $(8 \mathrm{hr}): 50(\max )$

In operation since (year): 1977

Irradiation device

No. and type of source: two $39 \mathrm{Ci}^{238} \mathrm{Pu}, \mathrm{Be}$ sources (2.90 TBq)

Total Activity/Output ( $\mathrm{n} / \mathrm{s}$ at source): $2.2 \times 10^{8} \mathrm{n} / \mathrm{s}$

Geometry: Partial Body, $10 \mathrm{~cm} \times 14 \mathrm{~cm}$ beam size, $S S D=60 \mathrm{~cm}$

Incident neutron flux density in body: $104 \mathrm{n} / \mathrm{cm}^{2} / \mathrm{sec}$

Exposure time: 1000 to $2000 \mathrm{sec}$

Uniformity of irradiation for element \& organ of interest: $10 \%$

Special features: Accurate kidney and liver localization accomplished

by ultrasonic scanning. Shield exceeds IAEA regulations for

certification as transportation container.

Counting device

No. and type of detector: two $25 \%$ eff. $\mathrm{Ge}(\mathrm{Li})$ detectors (res. $<2.5 \mathrm{keV}$ )

Geometry: $20 \mathrm{~cm}$ from center of neutron beam

Shielding: Boron-doped polyethylene and bismuth

Measurement time: 1000 to $2000 \mathrm{sec}$

Data evaluation: On-line computer-based multi-channel analyzer

Special features: In vivo detection limits $2.2 \mathrm{mg}$ in kidney and $1.5 \mathrm{\mu g} / \mathrm{g}$ in Tiver

Costs (approximate, for replacsment in 1981 in US

Irradiation device: $\$ 20,000$

Detector device: $\$ 30,000$

Electronics and data processing: $\$ 15,000$ to $\$ 50,000$ 

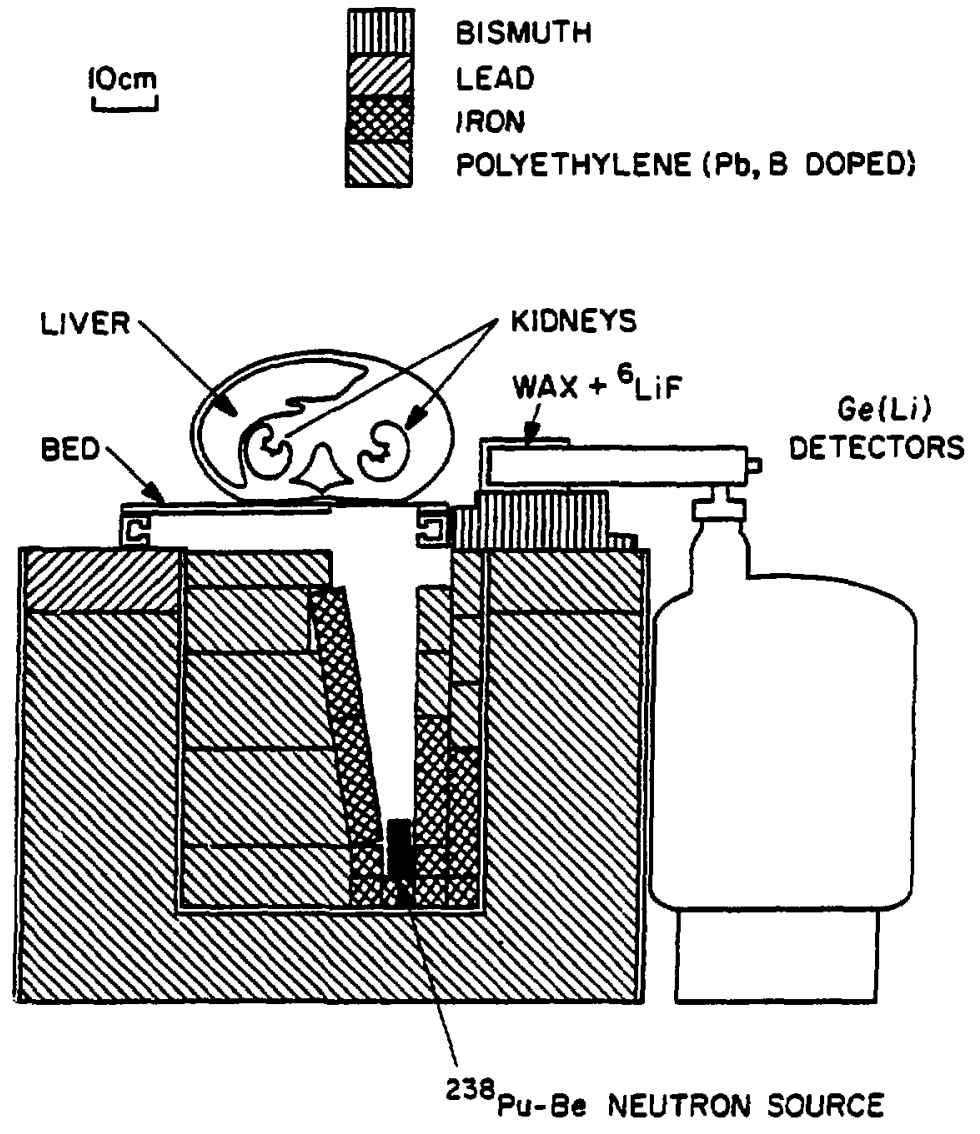


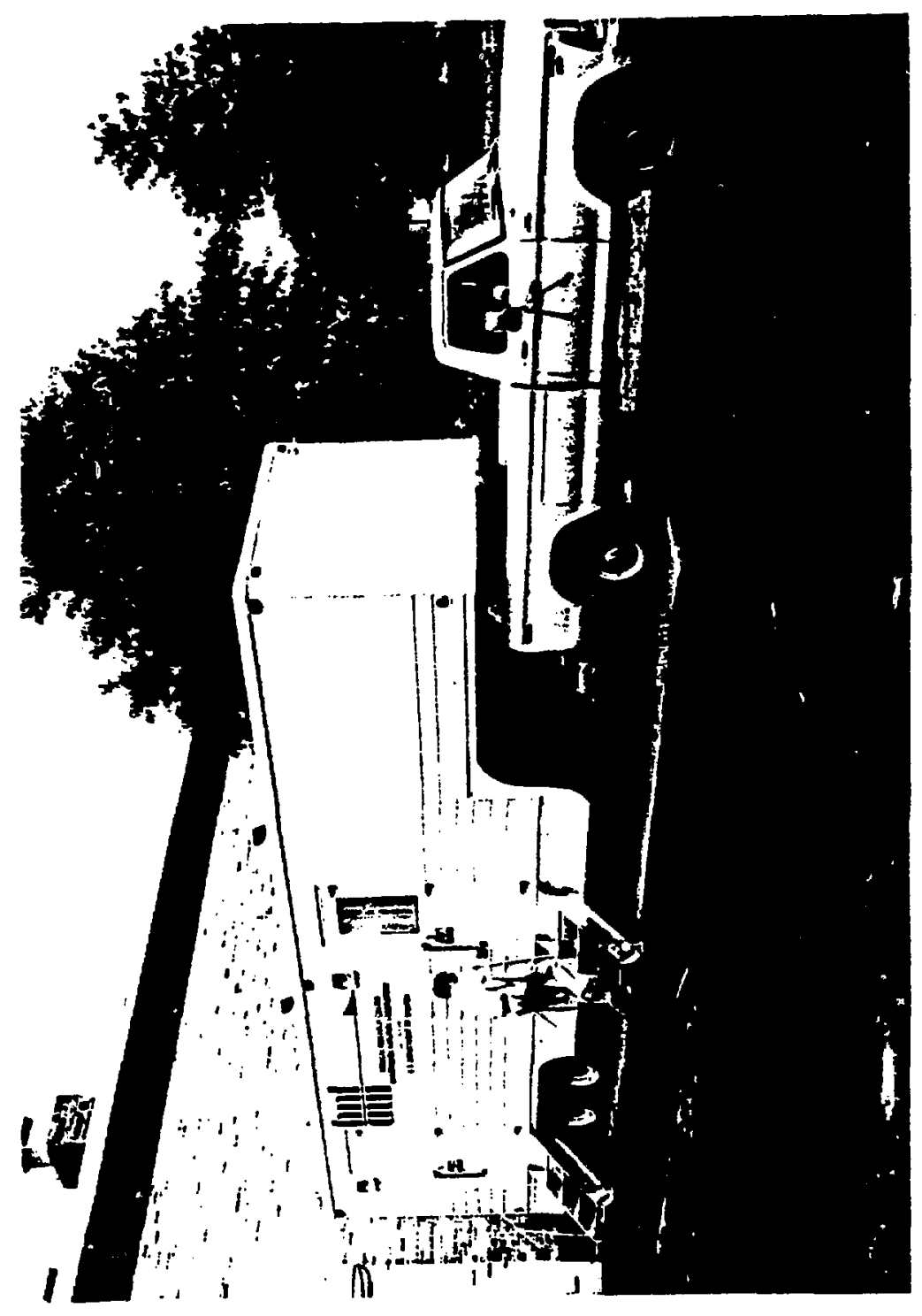


Appendix -7.4

DESCRIPTION OF SYSTEM FOR IN VIVO ANALYSIS BY

NUCLEAR RESONANT SCATTERING OF GAMMA RAYS

Institute address

Medical Research Center

Brookhaven National Laboratory

Upton, New York 11973, USA
Name of person to contact for more information

Dr. David Vartsky

(5i6) 282-3637

Dr. Stanton H. Cohn

(5i6) $282-3591$

\section{Overall system performance}

Element(s) measured: $\mathrm{Fe}$

Organ of interest: Liver, heart

Radiation dose: $100 \mathrm{mSv}$ (skin dose in the irradiated area)

Reproducibility of measurement: $6 \%$

No. of measurements possible per day $(8 \mathrm{hr}): 2$

In operation since (year): 1980

Irradiation device

No. and type of sourse: One ${ }^{56}$ Mn source in a quartz capsule

Total Activity/Output ( $\mathrm{n} / \mathrm{s}$ at source): $2 \cdot 1090$ photons/sec

Incident photon flux density in body: $1 \times 10^{6}$ photons $/ \mathrm{cm}^{2} \cdot \mathrm{sec}$

Exposure time: $2000 \mathrm{sec}$

Uniformity of irradiation for element \& organ of interest:

Special features: Gaseous source kept at $10000 \mathrm{C}$

Counting device

No. and type of detector: $2 \times$ HPGe detectors

Geometry: Positioned at $90^{\circ}$ to the incident photon beam

Shielding: Bi annulus around and $6 \mathrm{~mm}$ lead disc in front of detectors Measurement time: $2000 \mathrm{sec}$

Data evaluation: On-line computer based multi-channel analyzer system

Special features:

Costs (approximate, for replacement in 1981 in US\$)

Irradiation device: $\$ 10,000$

Detector device: $\$ 30,000$

Electronics and data processing: $\$ 18,000$ 


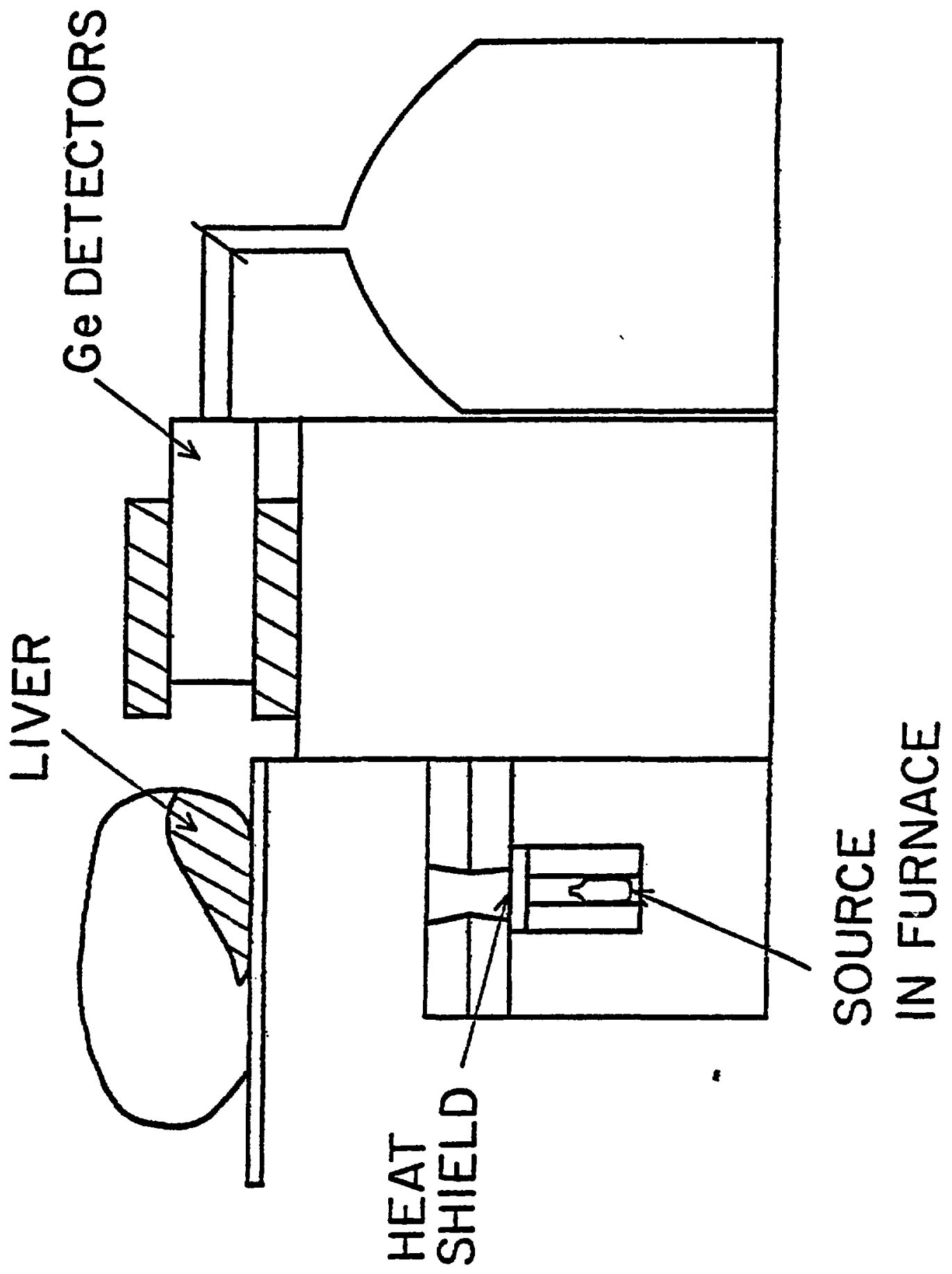


Append $1 x-7.5$

IN VIVO LEAD MEASUREMENT

Instituce address

Medical Research Center

Brookhaven National Laboratory

Upton, New York 11973, USA
Name of person to contact

for more information

Luclan Wielopolski

(516) 282-7107

Stanton H. Cohn

(516) 282-3591

\section{Overall system performance}

Element (s) measured:

Organ of interest:

Radiation dose:

Reproductbility of

$\mathrm{Sr}, \mathrm{Pb}, \mathrm{Zn}$

Bone (Iivia)

Skin $10 \mathrm{mGy}$ Bone marrow $0.2 \mathrm{mGy}$

No. of measurements possible per day $(8 \mathrm{hr})$ : 12-14

In operation since (year): Planned to start 1982

\section{Irradiation device}

$\begin{array}{ll}\text { No. and type of source: } & { }^{109} \mathrm{Cd} \text { or }{ }^{125} \mathrm{I} \\ \text { Total Activity/Output: } & 3.7 \mathrm{GBq}\end{array}$

Geometry:

Partial body $\left(1 \mathrm{~cm}^{2}\right.$ )

Incident neutron flux density in body:

Exposure time:

$30 \mathrm{~min}$

Untformity of irradiation for element \& organ of interest: Cortical bone nly Special features: Easy for transportation

Counting device

No. and type of detector:

Geometry:

Shlelding:

Measurement time:

Data evaluation:

Special features:
$1 \mathrm{Si}(\mathrm{L} i) \quad 80 \mathrm{~mm}^{2}$

90 degree configuration

around the source $\mathrm{Sn}$, S.S., detector $\mathrm{Cu}$ and $\mathrm{AI}$. 30 min manual

In vivo detection 1 imit at present $=20 \mu \mathrm{g} \mathrm{Pb} / \mathrm{g} \cdot$ wet

Coscs (approximate, for replacement in 1981 in US\$

Irradiation device:

Detector device

Electronics and daca processing:
$\$ 7,000.00$

$\$ 10,000.00$

$\$ 15,000.00$ 


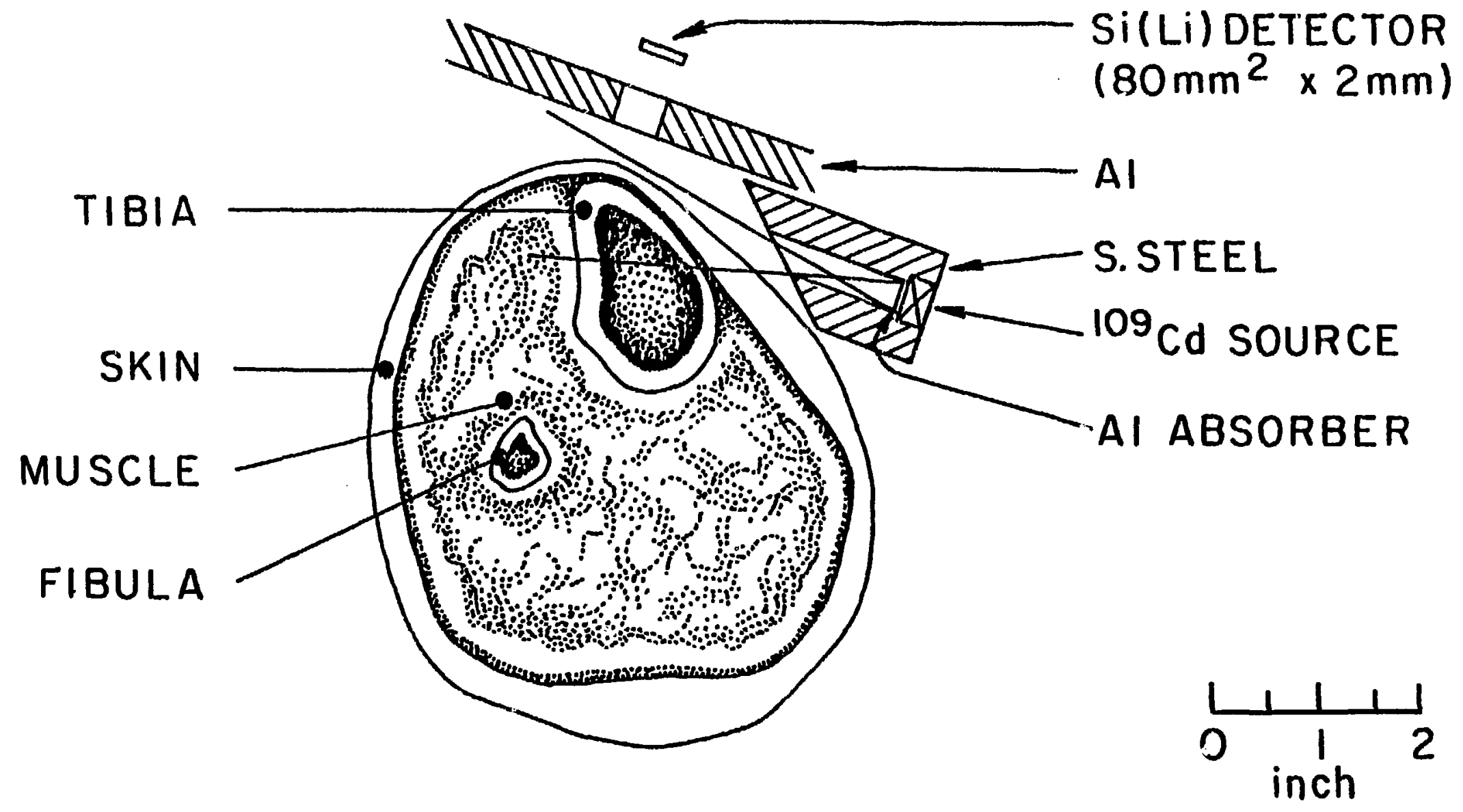

Configurat ton of the detertion system

and the source to measure lead in tibia. 